\title{
Environmental issue in an alternative production-maintenance control for unreliable manufacturing system subject to degradation
}

\author{
Ali Ben-Salem ${ }^{\mathrm{a}}$, Ali Gharbi ${ }^{\mathrm{a} *}$, Adnène Hajji ${ }^{\mathrm{b}}$ \\ ${ }^{\text {a }}$ Automated Production Engineering Department, École de Technologie Supérieure, Production System \\ Design and Control Laboratory, Université du Québec, Montreal, Canada; ${ }^{b}$ Department of Operations and \\ Decision Systems and CIRRELT, Laval University, Québec, Canada.
}

\begin{abstract}
This article addresses the problem of joint production, maintenance and emissions control for an unreliable manufacturing system subject to degradation. The manufacturing system is composed of a production unit producing one product type. The production operations generate harmful emissions to the environment and may be sanctioned by an environmental penalty imposed by the relevant authorities under the emission cap approach. Due to degradation phenomena, the availability of the machine decreases and the emission rate increases continuously over time. This paper aims to propose a feedback strategy to simultaneously control production rate, emission rate as well as maintenance rate in order to mitigate the effect of the degradation of the system. The objective is to minimize the total cost over an infinite horizon. In this article, we propose three different control policies HPP1, HPP2 and HPP3, which are analyzed and compared. Each control policy is characterized by a production and/or maintenance strategy different from the others policies, with or without the consideration of the emission aspect in the structure of the policy. An experimental resolution approach based on experimental design, simulation and response surface methodology is applied in order to determine the optimal control policies parameters. The results show that the proposed HPP3, which integrates the emission control in the production and maintenance strategy, gives a significant gain in term of total cost compared to HPP1 and HPP2. In addition, we integrate a preventive maintenance strategy to HPP3 in order to investigate a more general case. To illustrate the robustness of the proposed policies, several sensitivity analysis are presented to show the effect of system parameters on the structures of each policy. This analysis allows defining an overhaul and a preventive maintenance zones from the interactions between the parameters of HPP3.
\end{abstract}

Keywords: unreliable manufacturing system, degradation, emission, experimental approach, production, overhaul, preventive maintenance.

\section{Introduction}

The domain of manufacturing systems has undergone several changes over the years. Lately, in addition to economic requirements, social and environmental aspects are increasingly present. Production planning and control is among the topics that have received the attention of many researchers (Fernandes et al., 2009, Mckay 2003). 
A detailed review of the literature shows that the problem of production control has been considered by several authors. A significant branch of research has formulated the problem as an optimal control model based on the work of Kimemia and Gershwin (1983). They suggested a retroactive formulation of the control problem for a flexible manufacturing system. Policy founded had a specific structure called Hedging Point Policy (HPP) whose purpose is to control the production rate based on inventory level taking into account the state of the system. In the same direction, Akella and Kumar (1986) have succeeded in developing the analytical solution of the problem for a single machine producing a single type of product. Motivated by this work, many extensions have been developed in this area of research addressing the management of production planning from different perspectives. Caramanis and Sharifnia (1991) have increased the complexity by studying a multiple-part-type problem. A number of studies extended the control problem to investigate the maintenance of production unit (Berthaut et al. (2011), Chelbi and Ait-Kadi (2004)). Sethi and Zhang (1999), Bai and Elhafsi (1997) and Gharbi et al. (2006) considered the setup (cost and / or time) in the optimization of stochastic control problems. Other works focused on the reliability of suppliers in the supply chain such as Hajji et al $(2009,2011)$ and Parlar and Perry (1995). Radhoui et al (2009) and Rivera-Gómez et al. (2013a, 2013b) discussed the interaction between quality, maintenance and production control. In the context of flexible capacity, another study was developed by Gharbi et al. (2011); the authors treated the case of a production system consisting on a central machine which, in the case of a lack of capacity, has to use a reserve machine to meet the demand.

Despite the diversity of all these research studies, the environmental aspect (industrial discharges, pollutant emissions ...) and its influence on the production and maintenance planning in a dynamic stochastic context is not yet largely studied. However, in practice, the major problem for companies is to minimize costs through the best management of their production system and at the same time meets the environmental requirements regulated increasingly by the majority of industrialized countries. Today, for example, the consideration of harmful emissions in the industry represents a great ambiguity. Given the lack and the great need to focus on introducing the constraints dictated by the environmental requirements in the management of manufacturing systems, some researchers have begun to get closer to the industrial environment addressing a complex and practices issues. A series of contributions of Dobos $(1998,1999,2001)$ has been developed to determine the effect of environmental policy on production and inventory decisions. All these studies are based on a mathematical formalism in order to determine the environmental policy in the context of environment control approaches: taxes, emission penalty or trading permits. In these works, the author considers a production system which meets a demand rate. The control and state variables are the production rate and inventory level, respectively, in order to minimize the total cost function. Based on this work, $\mathrm{Li}$ and $\mathrm{Gu}$ (2012) compared the production-inventory control policy with and without the environmental requirements. Later, Li (2013) has introduced quality issue in the context of trading permit. On the other side, some studies have introduced the environment aspect in the economic order quantity EOQ model (Battini et al. (2014); Bouchery et al. (2012)). Chan et al. (2013) proposed an EOQ model considering emissions. Using an analytical approach, they provided the conditions in which the relative emission reduction is greater than the relative cost increase. Moreover, a few numbers of authors has studied the interaction between maintenance planning and environmental issue. Among these, Li (2014) proposed an alternative production-maintenance policy with 
deteriorating items with the consideration of an emission tax and pollution $R \& D$ investment. Chouikhi et al. (2012) considered a production system subject to failures which can cause demand backlog and have a negative effect on the environment. They determined the optimal maintenance period in order to optimize the maintenance cost and reduce environment discharges.

While all these papers study the effect of introducing the environmental aspect in the production and /or maintenance planning, to the best of our knowledge, no study has addressed the phenomena related to the equipment that may affect the emissions as the degradation in the context of production and maintenance control.

In an industrial environment, manufacturing systems are always subject to a gradual degradation over the time due mainly to the use of the system or a lack to make perfect maintenance activities (reset the system as good as new after corrective or preventive maintenance). In the literature, the manufacturing systems subject to gradual degradation over time has attracted the attention of many researchers. Based on the fact that machine availability decreases over time (Dhouib et al. 2008), different approaches have been developed to find a relationship between the availability and degradation of manufacturing equipment. More specifically, several studies have modeled the degradation of the machine considering the number of failure as an indicator of the degradation state (Lam (2004), Deyahem et al. (2011), Rivera-Gómez et al. (2013a)). Another approach consists on the use of the age of the machine to characterize degradation. In this sense, Love et al (2000) formulated the problem of a manufacturing system with a repair/replacement policy. They considered that corrective action can reduce partially the state of degradation. Recently, RiveraGómez et al. (2013b) have established a relationship between the quality and the degradation of a production system that can produce non-conforming parts. The authors presented the rejection rate based on the level of the equipment degradation. By referring to the latter work, the degradation phenomenon affects the performance and effectiveness of the system. Note that degradation has an impact on the availability of the system (Deyahem et al. $(2009,2011)$ ) and even on the quality of products (Rivera- Gómez et al. 2013a, 2013b), thus, we can assume that this degradation can have an effect on emissions generated by the production unit.

Actually, consideration of environmental issues at the operational level of decision-making is relatively new in the literature. Despite the existence of some progression, the interaction of the environmental aspects together with the increasing complexity and dynamic behaviour of manufacturing systems (degradation, maintenance...) is still an open subject in the scientific literature. In the same way, even international standards, such as ISO14000, provide targets and general objectives to achieve in term of environmental management but without too much detail on the operational level (Chan and Monahan, 2010). Hence, we need to expand our understanding of various phenomena that can influence the process of decision making. This paper aims to propose a new control policy that takes into account simultaneously the production and maintenance control of a manufacturing system which generates emissions. We will focus on the interaction between environmental issue and machine deterioration in a stochastic dynamic context. The problem is to determine the joint production, witch integrate emission, and overhaul policy that minimizes the incurred total cost: inventory, backlog, emission and maintenance cost. 
The rest of the paper is organized as follows. In section 2, the description of the system under study and the formulation of the control problem are defined. The proposed control policies are presented in section 3. Sections 4 and 5 present, respectively, the resolution approach and the simulation model developed. A numerical example is illustrated in section 6 , and sensitivity analysis is presented for various system parameters. In section7, we propose an extension of HPP3 by considering a preventive maintenance policy. Conclusions are given in Section 8 .

\section{Problème formulation}

\subsection{Description of the manufacturing system}

The manufacturing system under study consists on a single manufacturing facility subject to random failures, repairs and maintenance activities, which produces to meet the constant demand of a single product type. Among the characteristics of the manufacturing system under study, harmful emissions are generated during the production. We consider that the production of one item causes the release of a quantity of pollutant $\theta$ called emission index. The purpose of the production facility is to provide goods in order to satisfy the customer demand while respecting the environment requirements. Among these requirements, the emission cap approach where authorities can impose a standard emission limit $L$ per period $T$ and at each exceeding of $L$, a penalty should be paid for each emission unit (Chan and Monahan, 2010).

Figure 1 presents the manufacturing system considered:

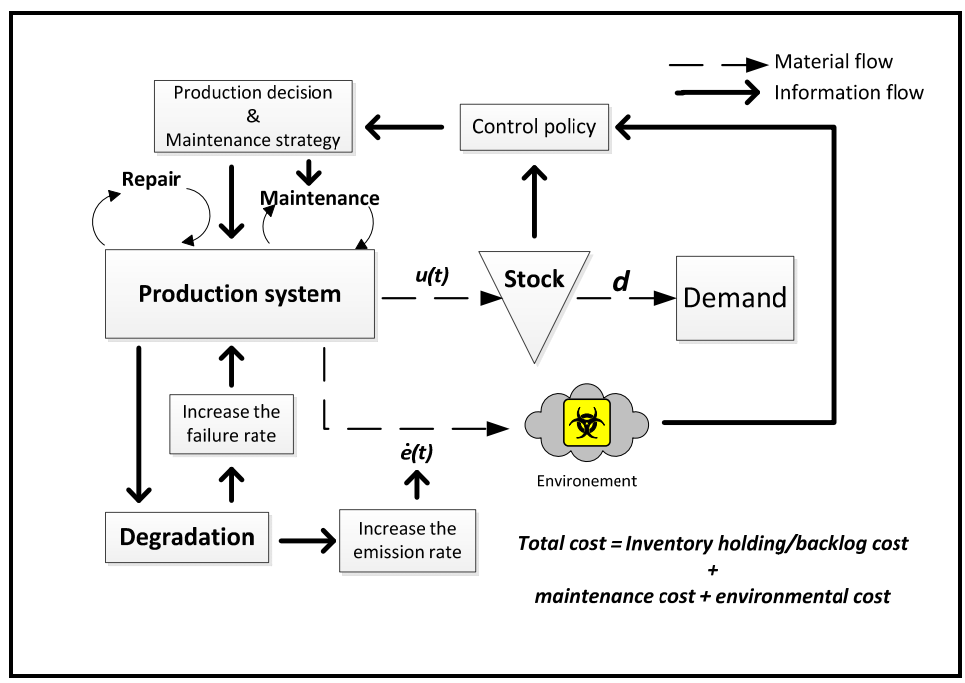

Figure 1: manufacturing system under study

We note that the production system degrades progressively over time which decreases its availability. We consider also that the degradation affects the emission rate $\dot{e}(t)$. In fact, many industries are facing this type of problem. We can take the example of the chemical or pharmaceutical industry; purification facility (Zhang and al., 2011) or filters (e.g. activated carbon filters) are used for the treatment of gases before emitting into the environment (Przepiórski (2006)). The principle of these filters consists on pollutant absorption to reduce the concentration of hazardous gases. However, their absorption characteristic decreases with the use over time. As result of this filter degradation, the emission rate increases. More specially, for 
carbon filters, when carbon is saturated (not able to absorb pollutants), the filter becomes inefficient, and a maintenance operation is required. At this level, we consider that maintenance activities are necessary to reduce the effects of degradation. Overhaul operation is a long and costly action which completely restores the machine (reliability and emission rate), to the initial conditions (as good as new AGAN). In the other hand, the corrective maintenance operation CM; less expensive, make the machine return to produce after the failure, but without any effect on its degradation (as bad as old ABAO). For a more general case, preventive maintenance PM can be defined between these two extreme maintenances ( $\mathrm{CM}$ and overhaul) as an activity that reduces proportionally the degradation of the machine.

\subsection{Control problem formulation}

\subsubsection{Problem statement}

The manufacturing system studied is subject to random events (failures and repair activities) and maintenance activities. Therefore, the system evolves through three discrete modes according to continuous time- discrete state stochastic process described by the random variable $\{\xi(t), t>0\}$; the machine is available when $\xi(\mathrm{t})=1$, it produces items and generates emissions. However, when the machine is down $\xi(\mathrm{t})=2$, a corrective maintenance CM operation is carried out. This type of minimal repair restores the system to the same state as before failure (ABAO) since the $\mathrm{CM}$ has no influence on the degradation state of the system. Then the emission and the failure rate remain at the same values as before repair. When $\xi(\mathrm{t})=3$, perfect maintenance (overhaul) restores the degradation effects and makes the system as new (AGAN). After overhaul, the system parameters $\theta$ and $q_{12}$ are returned to their initial values. During the maintenance operations, the manufacturing system doesn't emit pollutant since the production has been stopped.

We define $q_{i j}$ (.) as the transition rate from the state $\mathrm{i}$ to $\mathrm{j}, \mathrm{i} \neq \mathrm{j} ; \mathrm{i}, \mathrm{j}=\{1,2,3\}, \omega_{0}$ (.) a decision variable which controls the transition to the overhaul, $\omega_{0}()=.\mathrm{q}_{13}$. We assume that the transition to overhaul can be done only if the machine is operational $(\xi(t)=1)$.

Let $u(t)$ denotes the production rate and $d$ the constant demand rate at time t. The production rate, at any instant, must satisfy the capacity constraint of the machine given by the following equation:

$$
0 \leq u(t) \leq U_{\max }
$$

Where $U_{\max }$ is the maximum production rate.

The dynamics of the production surplus can be presented by the differential equation (2):

$$
\dot{x}(t)=u(t)-d, x(0)=x_{0}
$$

Where $x(t)$ denote the inventory level and $x_{0}$ its initial value.

We define the age $a(t)$ as the number of products which characterize the machine's history by an increasing function of the production rate since the last operational state of the machine. The cumulative age is presented by the differential equation (3): 


$$
\dot{\mathrm{a}}(\mathrm{t})=k_{1} \times u(t), \quad a\left(t_{r}\right)=0
$$

Where $t_{r}$ represents the last restart time of the machine after an overhaul, $k_{l}$ is a given positive constant.

The emission rate $e(t)$ can be defined by equation (4):

$$
\dot{e}(t)=u(t) \times \theta(a), \quad t \in\left[t_{i}, t_{i+1}\left[, e\left(t_{i}\right)=0, i=0, . ., \infty,\right.\right.
$$

Where $\theta(a)$ is the emission index (units of emission / unit produced) which is defined in our problem as a function of the age of the machine $a(t)$. Under the emission cap approach, in each reference period $T_{i}$, if the quantity of emissions exceeds a standard limit $L$ fixed by the relevant authorities, the excess quantity is penalized with an environmental cost. At the end of the reference period $T_{i}$, the emission counter is reset to zero.

\subsubsection{Degradation model}

The literature shows that several degradation models were used. In our case, we assume that the machine availability decreases (the failure rate $q_{12}$ increases) due to degradation. The failure rate of the machine can be expressed by the following expression:

$$
q_{12}(a)=q_{1}+q_{2}\left(1-e^{-k_{2} \frac{a(t)^{3}}{k_{3}}}\right)
$$

The failure rate of the machine is an increasing function of the age. Note that $q_{1}$ is the value of $q_{12}$ at the initial conditions, $q_{2}$ is the limit considered of deterioration, $k_{2}\left(0 \leq k_{2} \leq 1\right)$ is an adjustment parameter of the failure rate and $k_{3}$ is a positive given constant. The key idea is to relate the failure rate to the age. Initially, when $a(t)=0$, the machine breaks down with rate $q_{12}(a)=q_{1}$. Increasing the age, failure becomes more frequent $\left(q_{12}(a)\right)$. Ultimately, at an advanced age, the failure rate reaches its maximum value $q_{12}=q_{1}+q_{2}$.

This article leads to found a relationship between the age of the machine and the emissions index. In this way, the emission index is defined as an increasing function of the age of the machine. This relationship can be expressed by the following formula:

$$
\theta(a)=\theta_{0} \times e^{k_{4} \alpha a(t)}
$$

Where $\theta_{0}$ the value of $\theta$ at the initial conditions, $\alpha$ an adjustment parameter of the emission index $(0 \leq \alpha \leq 1)$ and $k_{4}$ a positive given constant.

Figure 2 shows the trajectory of the emission index and the failure rate as function of the age for different value of $\alpha$ and $k_{2}$, respectively: 

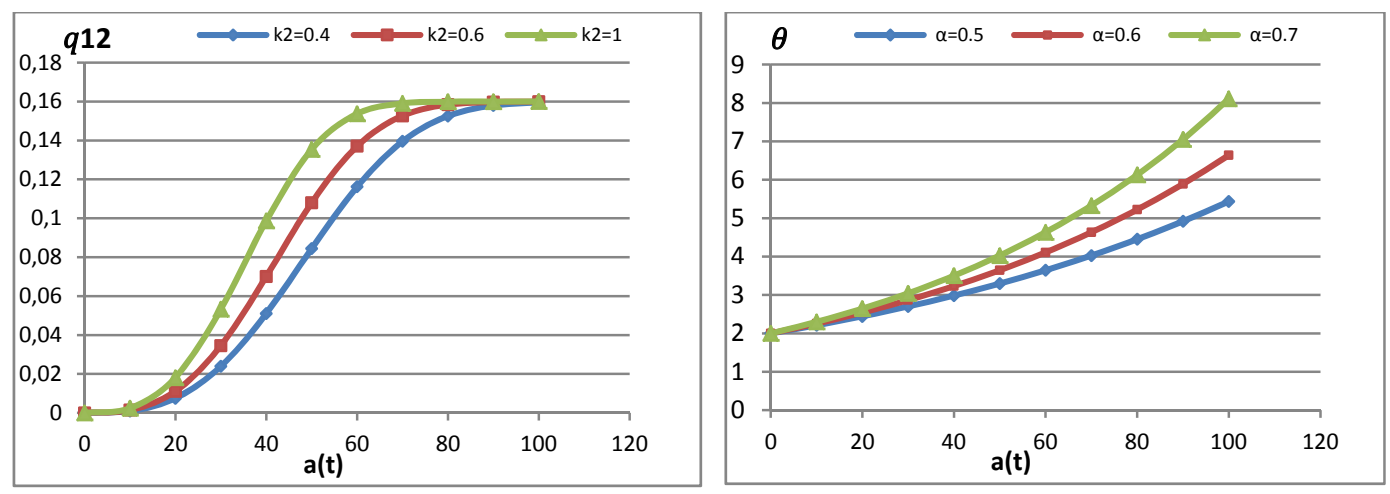

Figure 2: Effect of the degradation on $\mathrm{q}_{12}$ and $\theta$.

\section{Cost function and control policy}

\subsection{Cost function}

The instantaneous inventory, backlog and maintenance cost function $g($.) is given by the following equation:

$$
g(x(t))=C^{+} x^{+}+C^{-} x^{-}+C_{\text {Cor }} . \operatorname{Ind}\{\xi(\mathrm{t})=2\}+C_{\text {over }} \cdot \operatorname{Ind}\{\xi(\mathrm{t})=3\}
$$

Where $x^{+}=\max (0, x), x^{-}=\max (-x, 0), C^{+}$and $C^{-}$are positive constants used to penalize, respectively, the positive inventory and backlog. $C_{c o r}$ and $C_{\text {over }}$ represent the $\mathrm{CM}$ and overhaul cost, respectively.

The penalty emission cost at the end of reference periods $T_{i}$ is given by the following equation:

$$
E C\left(t_{T i}\right)=C^{e} \times \max \left(0, e\left(t_{T i}\right)-L\right), i=0, . ., \infty
$$

Using (7) and (8), the total cost function $J($.$) can be defined by the following equation.$

$$
J(x, e, \alpha, a)=\int_{0}^{\infty} e^{-\rho t} g(x(t)) d t+\sum_{i=1}^{\infty} C^{e} \times \max \left(0, e\left(t_{T i}\right)-L\right)
$$

Where $\rho$ is the discount rate.

The decision variables for this problem are $\left(u^{*}, \omega_{0}^{*}\right)$. The objective is to minimize the cost function (9) and simultaneously define the production and overhaul rates, as a function of the state of the system, the inventory level, the emission level and the age of the machine.

\subsection{Proposed control policies}

In this section, we present three joint production and overhaul policies. First, the equations defining the policies are presented. Then, we explain the structure of each policy through its parameters and present the reasons for proposing these control policies:

- HPP1 policy: over time, the manufacturing system production is controlled by a buffer stock control policy inspired from the well-known hedging point policy (HPP). The production policy is defined by the following equation: 


$$
u(t)=\left\{\begin{array}{cll}
U_{\max } & \text { if } & x<Z 1 \\
d & \text { if } & x=Z 1 \\
0 & \text { if } & x>Z 1
\end{array}\right.
$$

The manufacturing system is controlled over time by a classical HPP, as presented in the equation (10) where Z1 is the buffer stock capacity. The objective is to control the production rate depending on the inventory level and taking into account only the system state. This policy (HPP) allows better production control for unreliable manufacturing system in addition to the ease of implementation. For more details about this policy, we suggest the reader to consult the work of Akella and Kumar (1986).

The overhaul policy is defined by the following equation:

$$
\omega_{0}(.)=\left\{\begin{array}{cc}
1 & \text { if } \\
0 & \text { else }
\end{array} \quad a(t)>C a_{\text {over }}\right.
$$

Where $C a_{\text {over }}$ denotes the critical age level at which an overhaul is required. The overhaul policy consists in doing the major repair only when the age of the machine reaches a critical value $C a_{\text {over }}$. Recall that the machine is subject to degradation that affects not only the failure rate, but also the emission rate. The idea is to eliminate the effect of this degradation when the age of the machine reaches a critical value as in Rivera-Gómez et al. (2013b).

- HPP2 policy: for HPP2, we kept the same structure of the production policy which is presented in equation (10). However, the overhaul policy is different as presented in the following equation:

$$
\omega_{0}(.)=\left\{\begin{array}{cc}
1 & \text { if }
\end{array} \quad a(t)>C a_{\text {over }} \quad \text { and } \quad x(t) \geq X s \quad \text {; Where } X s \leq Z 1\right.
$$

Compared to HPP1, in the second policy (HPP2), the overhaul activity requires the presence of a comfortable inventory level $X s$, otherwise overhaul is delayed until the inventory level exceeds the value $X s$. Recall that the overhaul needs a high duration which increases the risk of backlog. The level $X S$ is defined as a safety stock in order to avoid additional backlog cost. In the same direction, several studies have proposed a maintenance strategies governed by inventory levels (Berthaut et al. (2010), Dhouib et al. 2012). The aim of this second policy is to improve the overhaul policy compared to HPP1.

- HPP3 policy: in the previous section, the production control policy described in equation (10) is the classical HPP. This policy control the production rate according to only the inventory level $x(t)$. However, in the context of environment control and protection, the manager should take into account the emission aspect in the production and maintenance planning. Thus, we consider that an adapted emission control level is beyond which he can decide to stop production if the 
emission cost rises. This decision cannot be taken independently of the inventory level, and thus a coupled feedback control should be considered. In light of this discussion, the HPP3 structure is defined by the following equations:

$$
\begin{aligned}
& \begin{array}{c}
\text { if e }(t) \leq Y \text { : apply HPP with a hedging Level } Z 1 \\
u(x, \alpha)=\left\{\begin{array}{clc}
U_{\max } & \text { if } & x(t)<Z 1 \\
d & \text { if } & x(t)=Z 1 \\
0 & \text { if } & x(t)>Z 1
\end{array}\right.
\end{array} \\
& \left\{\begin{array}{l}
\text { if e }(t)>Y \text { : apply HPP with a hedging Level } Z 2 \\
u(x, \alpha)=\left\{\begin{array}{cll}
U_{\max } & \text { if } & x(t)<Z 2 \\
d & \text { if } & x(t)=Z 2 \\
0 & \text { if } & x(t)>Z 2
\end{array} ; \text { Where } Z 1 \geq Z 2\right.
\end{array}\right.
\end{aligned}
$$

We define $r=Z 2 / Z 1,0 \leq r \leq 1$ to respect the condition $Z 1 \geq Z 2$.

Considering the importance and dangers of industrial discharges into the environment, the third control policy HPP3 is a multi-hedging point policy that takes into account the evolution of the emission level $e(t)$ over time. We propose to put another emission limit $Y$ (different from the standard emission limit $L$ imposed by the authorities) at which the production is reduced in order to minimize the emission cost. Production is continued at a slower rhythm maintaining a lower safety stock (Z2).

The structure of the overhaul policy is presented by the equation (15):

$$
\omega_{0}(.)=\left\{\begin{array}{cc}
1 & \text { if } \\
0 & \text { else }
\end{array} \quad a(t)>C a_{\text {over }} \quad \text { and } \quad x(t) \geq Z 2\right.
$$

For HPP3, the structure of overhaul policy defined in equation (15) is substantially the same as in HPP2 policy. However, in the case of HPP3, the threshold Z2, defined in the production policy, is considered as the comfortable inventory level before overhaul operation. It is important to note that HPP3 policy is proposed in order to measure the effectiveness of the new production policy (two critical thresholds Z1 and Z2) compared to the classical HPP proposed for HPP1 and HPP2.

In this paper, three different control policies are proposed. For the first policy HPP1, the emission issue is not explicitly present but the fact of considering overhaul allows mitigating emissions. In another side, the second policy HPP2 offers more control in the overhaul policy compared to HPP1 in order to minimize the backlog cost by considering the condition of the safety stock. Finally, the third policy HPP3 directly introduces the emission control from inventory level and target emission level. 
Our objective is to propose more way that allows managing these aspects and would like to study in detail the difference between them and find the best policy in specific contexts. An experimental resolution approach is applied to find optimal parameters of each control policy. The following section details the steps of this approach.

\section{Resolution approach}

In order to estimate the optimal cost value with respect to the each policy parameters, an approach combining simulation with experimental design and response surface methodology techniques is used (Gharbi et al. 2011). This approach is described in the following main steps:

\section{- $\quad$ Step 1: Description of the control policies}

In section 3.2, the structures of three policies are presented and expressed by mathematical equations.

\section{- $\quad$ Step 2: Simulation models}

Three simulation models are developed to reflect the system dynamics governed by each of the control policies considered. These policies are used as an input to conduct several experiments and thus evaluate the system performance. Section 5 provides more details on our simulation models.

- $\quad$ Step 3: Experimental design and response surface methodology

The experimental design approach defines the experiments number, the levels of the input factors (independent variables) considered and the variation extent of each factor. The analysis of variance is subsequently used to determine the main factors and their interactions which have a significant effect on the cost (dependent variable). Then, the response surface methodology allows obtaining the relationship between the dependent variable (cost) and significant main factors and their significant interactions. The resulting model is then optimized in order to determine the best combination of the control parameters which minimize the total cost.

\section{Simulation model}

Using the simulation language SIMAN under «ARENA» software, a combined discretecontinuous model is developed with $\mathrm{C}++$ routines for each control policy. Lavoie et al. (2010) showed the advantage of using this combination in terms of simulation time and reproducibility of the system dynamics. Figure 3 presents the diagram of the simulation model.

After initializing the model parameters required for the simulation $\left(Z 1, Z 2, U_{\max }\right.$, time step ...) (bloc 1), the manufacturing system (bloc 3) allows producing parts according to production policy (bloc 7) described by equations (10) or (13) and (14) to meet the demand rate (bloc 2). The machine is subject to random failures and repair activities (bloc 4). Therefore, the age of the machine increases over time and equipment degradation increases too (bloc 5). The state equations (bloc 8) describe the variation of inventory level $x(t)$ and the emission level $e(t)$ which takes into account the degradation state of the machine $\left(q_{12}(a)\right.$ and $\left.\theta(a)\right)$. At a certain level of degradation, the overhaul policy (bloc 6) determines the execution time of an overhaul operation when the conditions imposed by equations (11) or (12) or (15) are satisfied. The simulation time advances (bloc 9) and the model updates the inventory level and the emission level (bloc 10). At the end of the control period $T_{i}$, the emission level $e(t)$ is set to zero (bloc 11). Finally, we calculate the cost according to the variables of inventory and backlog levels ( $x^{+}$and $\left.x^{-}\right)$, the emission penalty, and the maintenance costs (bloc 12). 
The only difference between the three models (for the three policies) is in the definition of the structure of the control policy (bloc 6 and 7).

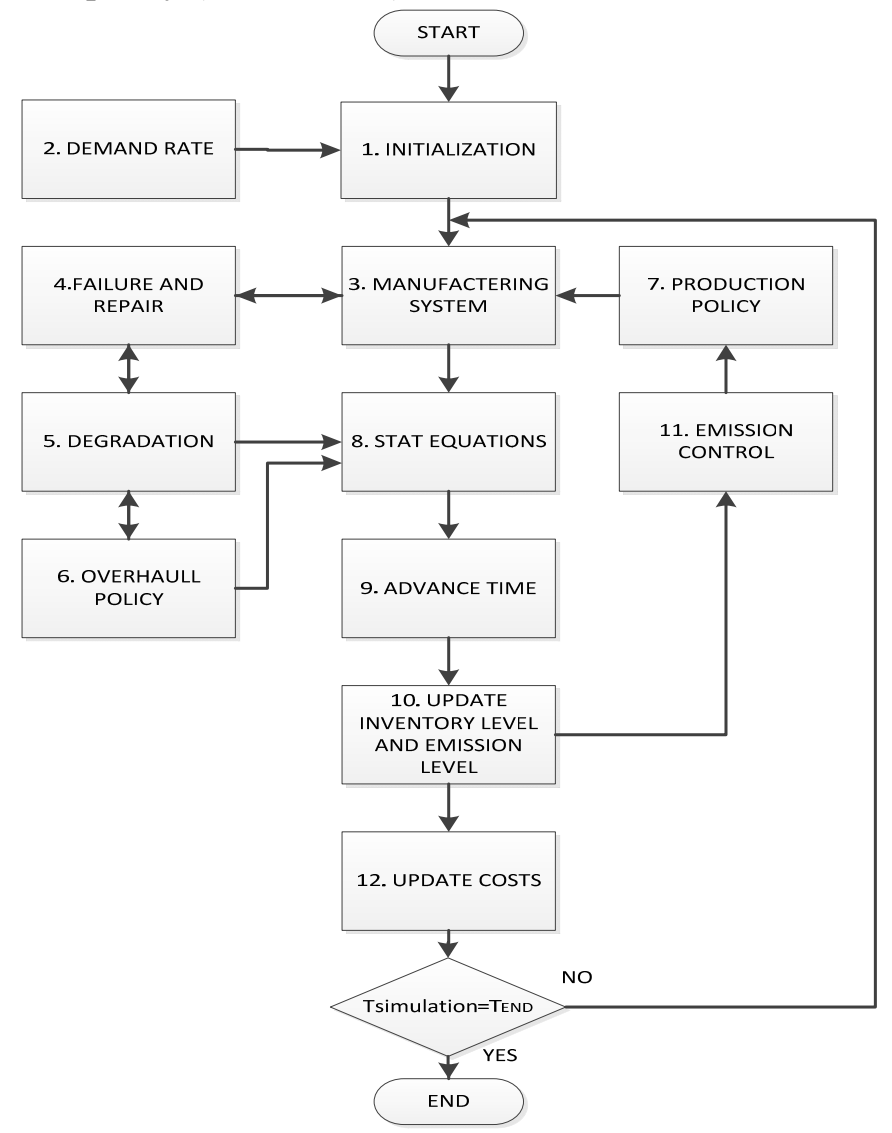

Figure 3: Diagram of the simulation model.

In order to validate that the simulation model adequately represents the system under study, we present the evolution of the inventory level $x(t)$, the emission level $e(t)$ and the age level $a(t)$ over time generated by the simulator when the HPP3 is applied. Figure 4 presents the results obtained when the parameters are set to $Z 1=20, Z 2=10, C a_{\text {over }}=70, Y=85, L=60$ and $T_{i}=140$ time unit (TU). 


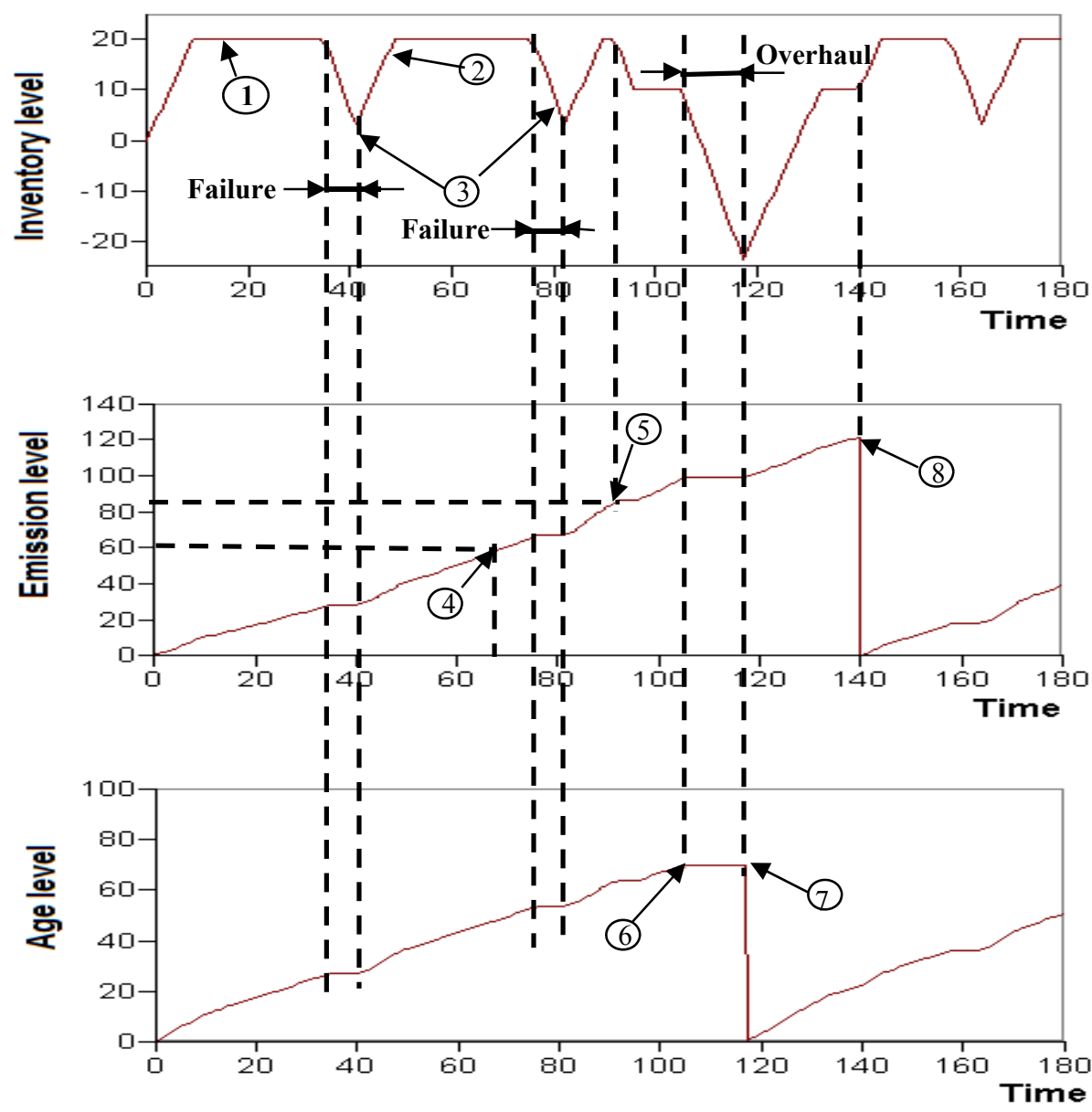

Figure 4: Trajectory of inventory, emission and age levels over time.

According to Figure 4, we note that, when:

- $0 \leq \mathrm{t}<68 \mathrm{TU}$; the emission level and the age level increase as function of the production rhythm. The manufacturing system produces according to classical HPP with a critical inventory threshold $Z 1=20$; production rate $u(t)=d$ (1) if $x(t)=Z 1$ and $u(t)=U_{\max }$ (2) if $x(t) \leq Z 1$. When a random failure event occurs (3), the production is stopped, thus the emission and the age levels remain at the same values. Production is restarted after a random repair activity.

- $68 \leq \mathrm{t}<92 \mathrm{TU}$, the simulation time advance and the emission level reaches the limit $L$ at $\mathrm{t}=68$ TU(4), consequently an emission cost is added to other costs (inventory, backlog and maintenance).

- $92 \leq \mathrm{t}<104 \mathrm{TU}$, the emission level $e(t)$ reached the level $Y$ at $\mathrm{t}=92 \mathrm{TU}$ (5) resulting to the production stop. From this moment, the critical inventory threshold decreases to $Z 2=10$ compared to $Z 1=20$ before this time. Then, production continues normally and the degradation state increases.

- $104 \leq \mathrm{t}<118 \mathrm{TU}$, the machine degradation reaches an advanced stage and at $\mathrm{t}=104 \mathrm{TU}, a(t)$ is equal to $C a_{\text {over }}=70$ (6). After checking that the condition of safety stock $(x(t) \geq Z 2)$ is 
satisfied, production is stopped and first overhaul operation is carried out in order to return the machine to (AGAN) condition. From the trajectory of inventory level $x(t)$, we note that the operation overhaul can cause a shortage of stock.

- $\mathrm{t}=118 \mathrm{TU}$, overhaul operation is finished $(7)$, so the age of the machine; the failure rate and the emission rate are restored to the initial values.

- $118<\mathrm{t} \leq 140 \mathrm{TU}$, the emission level continues to increase over time until the end of the emission control period at $\mathrm{t}=140 \mathrm{TU}$ (8). From this moment, the emission level is reset to zero and the production continue but with the critical inventory threshold Z1.

Based on several illustrations of this type, we can affirm that our simulation models adequately describe the dynamic of the manufacturing system under study.

\section{Experimental design and response surface methodology}

This section presents the third step of the resolution approach. Given the convexity of the cost function for this type of problem, we define three levels for each policy factor. The objective is to find the optimal parameters values of each policy.

\subsection{Numerical example}

The different parameters of operations and costs characterizing the system under study are as follows:

Table 1 : Parameter values

\begin{tabular}{|c|c|c|c|c|c|c|c|c|c|c|}
\hline Parameters & d & $\mathbf{U}_{\max }$ & $\mathbf{L}$ & $\theta_{0}$ & $\mathbf{q}_{1}$ & $\mathbf{q}_{2}$ & $\mathbf{q}_{12}$ & $\mathbf{q}_{31}$ & $\alpha$ & \\
\hline Value & 2 & 3 & 80000 & 2 & 0.0042 & 0.0044 & 0.1 & 0.05 & 0.6 & \\
\hline Parameters & $\mathbf{C}^{+}$ & $\mathbf{C}^{-}$ & $\mathbf{C}^{\mathrm{e}}$ & $\mathrm{C}_{\text {cor }}$ & $\mathbf{C}_{\text {over }}$ & k1 & k2 & k3 & k4 & $\mathbf{T}$ \\
\hline Value & 1 & 75 & 25 & 5000 & 100000 & 0.023 & 0.6 & $-2.10^{4}$ & 0.02 & 1 year \\
\hline
\end{tabular}

We adopt the complete factorial design $\left(3^{2}\right.$ for HPP1 and $3^{3}$ for HPP2). This type of plan gives more precise results since each interaction is estimated separately. Regarding HPP3, the number of factors is greater than three, thus we choose the Box-Behnken factorial design which is usually very efficient in terms of the number of required runs (Montgomery, 2005). The duration of each simulation is $1.000 .000 \mathrm{TU}$ to insure that the steady-state is reached. For each combination of values, five replications are made.

\subsection{Results analysis}

In this section, we present the results of the application of the resolution approach to the numerical example. Throughout this paper, the statistical treatment of the data is carried out using the «STATGRAPHICS» software. The results of the control parameters optimization of the three policies are summarized in Table 2.

From Table 2, we note that the correlation coefficients $\mathrm{R}_{\text {adjusted }}^{2}$ found are higher enough to judge the good quality of the models. In the same direction, an analysis of the residual normality and of the homogeneity of variance was also carried out to check the conformity of the models.

The second order models for the three proposed control policies are given by: 


$$
\begin{aligned}
& \widehat{\operatorname{Cost}}_{H P P 1}=427.074-3.19173 \times Z 1-1.80408 \times C a_{\text {over }}+0.0175362 \times Z 1^{2}+0.00267334 \times Z 1 \times \\
& C a_{\text {over }}+0.0124261 \times C a_{\text {over }}^{2} \\
& \widehat{C o s t}_{H P P 2}=410,275-2.80064 \times Z 1-12.4918 \times p-2.02378 \times C a_{\text {over }}+0.0165707 \times \\
& Z 1^{2}-0.106157 \times Z 1 \times p+0.00170812 \times Z 1 \times C a_{\text {over }}+16.2192 \times p^{2}+0.0146577 \times C a_{\text {over }}^{2} \\
& \widehat{\operatorname{Cost}}_{H P P 3}=570.55-0.014968 \times Y-3.4844 \times Z 1-214.679 \times r-1.48338 \times C a_{\text {over }}+ \\
& 6.51902 \times 10^{-7} \times Y^{2}+9.15854 \times 10^{-5} \times Y \times Z 1-0.000100067 \times Y \times C a_{\text {over }}+ \\
& 0.0145241 \times Z 1^{2}+162.703 \times r^{2}+0.0185879 \times C a_{\text {over }}^{2}
\end{aligned}
$$

Figure 5 presents the cost response surfaces when HPP3 is applied.

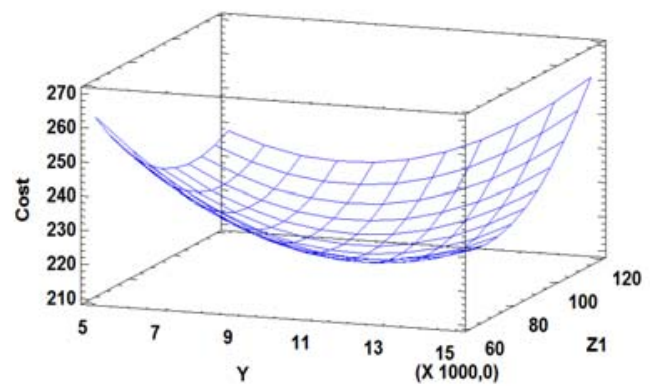

\begin{tabular}{|c|c|c|c|c|c|}
\hline Control policy & Factor & $\begin{array}{c}\text { Optimum } \\
\text { values }\end{array}$ & Cost* $^{*}$ & $\mathbf{R}_{\text {adjusted }}^{2}$ & Confidence interval ( $95 \%)$ \\
\hline \multirow{2}{*}{ HPP1 } & $Z 1$ & 86 & \multirow{2}{*}{232.43} & \multirow{2}{*}{$99.03 \%$} & \multirow{2}{*}[230.52;233.79]{} \\
\hline & $\boldsymbol{C a} a_{\text {over }}$ & 63.32 & & & \\
\hline \multirow{3}{*}{ HPP2 } & $Z 1$ & 83 & \multirow{3}{*}{224.58} & \multirow{3}{*}{$97.74 \%$} & \multirow{3}{*}[223.41;224.86]{} \\
\hline & $X s$ & 56 & & & \\
\hline & $C a_{\text {over }}$ & 64.21 & & & \\
\hline \multirow{4}{*}{ HPP3 } & $Z 1$ & 86 & \multirow{4}{*}{218.75} & \multirow{4}{*}{$95,17 \%$} & \multirow{4}{*}[217.64;219.21]{} \\
\hline & $Z 2$ & 56 & & & \\
\hline & $\boldsymbol{C a} a_{\text {over }}$ & 68.675 & & & \\
\hline & $Y$ & 10579 & & & \\
\hline
\end{tabular}

Figure 5: Cost response surfaces for HPP3.

To cross-check the validity of our models, we confirm that the optimal cost for each control policy falls within the confidence interval at $95 \%\left(\overline{\mathrm{C} . \mathrm{T}} \pm \mathrm{t}_{1-(\alpha / 2)}^{\mathrm{n}-1} \sqrt{\mathrm{S}^{2} / \mathrm{n}}\right)$ equivalent (Table 2$)$. This confidence interval obtained using $n=100$ replications of the simulation model, where $\overline{\mathrm{C}}$. $\mathrm{T}$ is the average optimal cost and $\mathrm{S}$ is the sample standard deviation.

Table 2: optimum values of the variables.

From Table 2, for selected system parameters (Table 1), we conclude that the safety stock constraint introduced in the overhaul policy gives an advantage to HPP2 compared to HPP1 with an improvement of $3.37 \%$ in total cost. Indeed, HPP 2 reduces the backlog cost through the safety stock condition before the overhaul activities. The results also show that HPP3 policy is the best in terms of total cost with an improvement of 5.88\% and $2.6 \%$ compared to HPP1 and HPP2, respectively. Indeed, HPP3 has two advantages; first, in the production policy, the emission level is taken into consideration which reduces the emission cost. Second, in the maintenance policy, a safety stock is required to carry out the overhaul operations which reduce backlog cost. 


\subsection{Sensitivity analysis}

The objective of this analysis is to demonstrate the efficiency and robustness of our resolution approach and to study the impact of the variation of the cost parameters on the each control policy performance. Table 3 summarizes the results of this sensitivity analysis compared to the basic case.

The variation of each parameter is analysed as follow:

- Variation of $\mathrm{C}^{+}$and $\mathrm{C}^{-}$: the variation of $\mathrm{C}^{+}$and $\mathrm{C}^{-}$has an opposite effect on the policies parameters. Indeed,_when $\mathrm{C}^{+}$decreases (case 1) (respectively $\mathrm{C}^{-}$increases (case 4)), the critical threshold ( $Z 1$ for HPP1 and HPP2, Z1 and Z2 for HPP3) and the level of safety stock ( $X S$ for HPP2 and $Z 2$ for HPP3) increase to benefit from the low holding cost (respectively to avoid additional backlog cost) leading to an increase of emissions. Therefore, the system reacts by reducing the critical age $\mathrm{Ca}_{\text {over }}$, for the three policies, in order to carry out more overhauls which reduce the emission rate. The opposite occurs when $\mathrm{C}^{+}$increases (case 2) (respectively $\mathrm{C}^{-}$ decreases (case 3)).

- Variation of $C^{\mathrm{e}}$ : when $\mathrm{C}^{\mathrm{e}}$ (case 5) decreases, the total emission cost decreases. In this case, less overhaul actions are conducted. This explains the increase in the critical age $C a_{\text {over }}$ (for the three policies). Therefore, the risk of shortages are reduced which requires less safety stock ( $X S$ for HPP2 and Z2 for HPP3 decrease). When $\mathrm{C}^{\mathrm{e}}$ increases (case 6), the opposite occurs.

- Variation of $\mathrm{C}_{\text {over }}$ and $\mathrm{C}_{\text {cor: }}$ : the variation of $\mathrm{C}_{\text {over }}$ and $\mathrm{C}_{\text {cor }}$ has an opposite effect on the policies parameters. Indeed, decreasing $\mathrm{C}_{\text {over }}$ ( 7 cases) (respectively $\mathrm{C}_{\text {cor }}$ increases (case 10)), more overhaul is conducted (respectively less $\mathrm{CM}$ is conducted), leading to a decrease in the critical age $C a_{\text {over }}$ (for the three policies). Consequently, the level of safety stock ( $X S$ for HPP2 and Z2 for HPP3) increase to protect system against shortage risks. The opposite occurs when $\mathrm{C}_{\text {over }}$ increases (case 8) (respectively $\mathrm{C}_{\text {cor }}$ decreases (case9)).

- Variation of the adjustment parameter $\alpha$ : from Table 3, the adjustment parameter $\alpha$ has an effect on the overhaul and production policy. When $\alpha$ decreases (case 11), the emissions rate decreases. Thus, $C a_{\text {over }}$ increases in order to execute less overhaul operations which need less safety stock ( $X s$ for HPP2 and Z2 for HPP3 decrease). The opposite occurs when $\alpha$ increases (case 12). 
Table 3: Results of the sensitivity analysis

\begin{tabular}{|c|c|c|c|c|c|c|c|c|c|c|c|c|c|c|c|c|c|c|c|}
\hline \multirow{2}{*}{ Case } & \multicolumn{6}{|c|}{ Parameters } & \multicolumn{3}{|c|}{ HPP1 } & \multicolumn{4}{|c|}{ HPP2 } & \multicolumn{5}{|c|}{ HPP3 } & \multirow[b]{2}{*}{ Remark } \\
\hline & $\mathbf{C}^{+}$ & $\mathbf{C}^{-}$ & $\mathrm{C}^{\mathrm{e}}$ & $\mathbf{C}_{\text {over }}$ & $\mathrm{C}_{\text {cor }}$ & $\alpha$ & $\mathbf{Z 1 *}$ & $C a_{\text {over }}$ * & Cost* & Z1* & $\mathbf{X s}{ }^{*}$ & $C a_{\text {over }}$ * & Cost* & $\mathbf{Z 1 *}$ & $\mathbf{Z 2 *}$ & $\mathbf{Y}^{*}$ & Ca $_{\text {over }}{ }^{*}$ & Cost* & \\
\hline- & 1 & 75 & 25 & 100000 & 5000 & 0.6 & 86 & 63.32 & 232.43 & 83 & 56 & 64.21 & 224.58 & 86 & 56 & 10579 & 68.67 & 218.75 & basic case \\
\hline 1 & 0.8 & 75 & 25 & 100000 & 5000 & 0.6 & 92 & 62.68 & 215.83 & 89 & 62 & 63.8 & 208.47 & 95 & 62 & 10007.3 & 66.24 & 201.83 & $\mathrm{Z} 1^{* \uparrow} \uparrow,\left(\mathrm{Z} 2^{*}, \mathrm{Xs}^{*}\right) \uparrow, \mathrm{Y}^{*} \downarrow, \mathrm{Ca}^{*} \downarrow$ \\
\hline 2 & 1.2 & 75 & 25 & 100000 & 5000 & 0.6 & 81 & 63.96 & 247.9 & 77 & 51 & 64.61 & 239.51 & 76 & 50 & 11481.7 & 71.83 & 233.94 & $\mathrm{Z} 1 * \downarrow,\left(\mathrm{Z} 2 *, \mathrm{Xs}^{*}\right) \downarrow, \mathrm{Y} * \uparrow, \mathrm{Ca}^{*} \uparrow$ \\
\hline 3 & 1 & 45 & 25 & 100000 & 5000 & 0.6 & 67 & 66.48 & 213.67 & 63 & 38 & 64.51 & 207.37 & 62 & 41 & 12224.3 & 70.95 & 203.17 & $\mathrm{Z}^{*} \downarrow,\left(\mathrm{Z} 2^{*}, \mathrm{Xs} *\right) \downarrow, \mathrm{Y} * \uparrow, \mathrm{Ca}^{*} \uparrow$ \\
\hline 4 & 1 & 105 & 25 & 100000 & 5000 & 0.6 & 95 & 58.7 & 245.54 & 93 & 66 & 63.54 & 238.73 & 101 & 67 & 9136.91 & 66.88 & 226.97 & $\mathrm{Z} 1^{* \uparrow},\left(\mathrm{Z}^{*}, \mathrm{Xs}^{*}\right) \uparrow, \mathrm{Y}^{*} \downarrow, \mathrm{Ca}^{*} \downarrow$ \\
\hline 5 & 1 & 75 & 20 & 100000 & 5000 & 0.6 & 86 & 71.61 & 229.33 & 83 & 55 & 71.61 & 221.4 & 86 & 54 & 11196.5 & 77.5 & 215.64 & $\mathrm{Z} 1^{*} \leftrightarrow,\left(\mathrm{Z}^{*}, \mathrm{Xs} *\right) \downarrow, \mathrm{Y}^{*} \uparrow, \mathrm{Ca}^{*} \uparrow$ \\
\hline 6 & 1 & 75 & 30 & 100000 & 5000 & 0.6 & 86 & 56.72 & 234.17 & 83 & 57 & 57.81 & 226.39 & 86 & 57 & 10351.7 & 63.46 & 220.31 & $\mathrm{Z}^{*} \leftrightarrow,\left(\mathrm{Z} 2^{*}, \mathrm{Xs}^{*}\right) \uparrow, \mathrm{Y}^{*} \downarrow, \mathrm{Ca}^{*} \downarrow$ \\
\hline 7 & 1 & 75 & 25 & 80000 & 5000 & 0.6 & 86 & 51.12 & 216.21 & 83 & 57 & 55.25 & 209.19 & 86 & 57 & 10189.5 & 61.43 & 204.07 & $\mathrm{Z} 1^{*} \leftrightarrow,\left(\mathrm{Z} 2^{*}, \mathrm{Xs}^{*}\right) \uparrow, \mathrm{Y}^{*} \downarrow, \mathrm{Ca}^{*} \downarrow$ \\
\hline 8 & 1 & 75 & 25 & 120000 & 5000 & 0.6 & 86 & 71.47 & 246.18 & 83 & 55 & 70.87 & 238.24 & 86 & 55 & 11033 & 75.14 & 232.15 & $\mathrm{Z} 1^{*} \leftrightarrow,\left(\mathrm{Z}^{*}, \mathrm{Xs}^{*}\right) \downarrow, \mathrm{Y}^{* \uparrow}, \mathrm{Ca}^{* \uparrow}$ \\
\hline 9 & 1 & 75 & 25 & 100000 & 3000 & 0.6 & 86 & 65.6 & 220.55 & 83 & 55 & 66.19 & 212.7 & 86 & 55 & 10676.7 & 70.39 & 206.83 & $\mathrm{Z} 1^{*} \leftrightarrow,\left(\mathrm{Z}^{*}, \mathrm{Xs}^{*}\right) \downarrow, \mathrm{Y}^{*} \uparrow, \mathrm{Ca}^{*} \uparrow$ \\
\hline 10 & 1 & 75 & 25 & 100000 & 7000 & 0.6 & 86 & 60.83 & 244.16 & 83 & 57 & 62.04 & 236.34 & 86 & 57 & 10485.6 & 66.91 & 230.59 & $\mathrm{Z}^{*} \leftrightarrow,\left(\mathrm{Z}^{*}, \mathrm{Xs}^{*}\right) \uparrow, \mathrm{Y}^{*} \downarrow, \mathrm{Ca}^{*} \downarrow$ \\
\hline 11 & 1 & 75 & 25 & 100000 & 5000 & 0.55 & 86 & 71.99 & 227.2 & 83 & 55 & 71.67 & 219.58 & 86 & 54 & 11051.4 & 76.09 & 217.69 & $\mathrm{Z} 1 * \leftrightarrow,\left(\mathrm{Z} 2 *, \mathrm{Xs}^{*}\right) \downarrow, \mathrm{Y}^{* \uparrow}, \mathrm{Ca}^{* \uparrow}$ \\
\hline 12 & 1 & 75 & 25 & 100000 & 5000 & 0.65 & 86 & 54.84 & 236.37 & 83 & 60 & 59.98 & 230.27 & 86 & 62 & 9143.01 & 60.15 & 222.62 & $\mathrm{Z} 1 * \leftrightarrow,\left(\mathrm{Z} 2 *, \mathrm{Xs}^{*}\right) \uparrow, \mathrm{Y}^{*} \downarrow, \mathrm{Ca}^{*} \downarrow$ \\
\hline
\end{tabular}


For HPP3, the variation of the system parameters has an effect on the level $Y$. In all the cases, the level $Y$ moves in the opposite direction of the critical threshold $Z 1$ and/or $Z 2$. Indeed, we note that if the values of $Z 1$ and/ or $Z 2$ increase, the system produce more at the maximum rate $\left(U_{\max }\right)$ which increases the emission cost in particular, and the total cost in general. To limit this increase, the system reacts by reducing the values of $Y$, leading to an earlier stoppage of production. The opposite occurs when $\mathrm{Z1}$ and/or Z2 decrease.

From all numerical examples analyzed in this study, it seems that the results are logical and the structures of the policies are always maintained. In general, the parameters of the control policies are influenced by the variation in the system parameters. In another had, from Table 3 , in all cases studied, the obtained results show that, first, HPP2 remains better than HPP1in term of total cost with an improvement around 3\%. Second, the policy HPP3 remains the best in terms of total cost incurred. The gain of HPP3 can reaches $7.56 \%$ and $4.93 \%$ compared to HPP1 and HPP2, respectively. Thus, in the next section, we focus on further improving of the structure of this policy. In this context, a preventive maintenance policy is developed in order to investigate a more general case for HPP3.

\section{Extension of HPP3: Preventive maintenance policy}

Over time, the failure and the emission rates increase due to the machine degradation. The role of the overhaul operation is to eliminate the effect of this degradation and make the machine AGAN. Since this perfect maintenance is very expensive, in this section, we assume that less perfect preventive maintenance (PM) activities are possible in order to reduce the maintenance cost.

The PM defines a fourth state of the system $\xi(\mathrm{t})=4$. We define $\omega_{\mathrm{p}}($.$) a decision variable which$ controls the transition to PM. We assume that the transition to PM can be done only if the machine is operational $(\xi(\mathrm{t})=1)$, thus $\omega_{\mathrm{p}}()=.\mathrm{q}_{14}$.

We consider that PM reduces proportionally the age of the machine compared to its value before maintenance activity. This method is called an arithmetic reduction of the age (Rivera-Gómez et al. 2013b). The effect of PM on the age of the machine is given by the following equation:

$$
a(t)^{+}=a(t)^{-}-\sigma a(t)^{-}
$$

Where $\sigma,(0 \leq \sigma \leq 1)$, is the parameter of the PM efficiency, $\mathrm{a}^{-}$is the age of the machine before $\mathrm{PM}$ and $\mathrm{a}^{+}$is the age after PM. The key idea is to modelize the case between the two extreme maintenance activities (overhaul and $\mathrm{CM}$ ). Indeed, if $\sigma=0$; PM is a minimal maintenance and equivalent to $\mathrm{CM}$, if $\sigma=1$; PM is a perfect maintenance similar to overhaul.

Figure 6 presents the trajectory of the emission index and failure rate as function of the age when PM efficiency is set to $\sigma=0.3$ : 

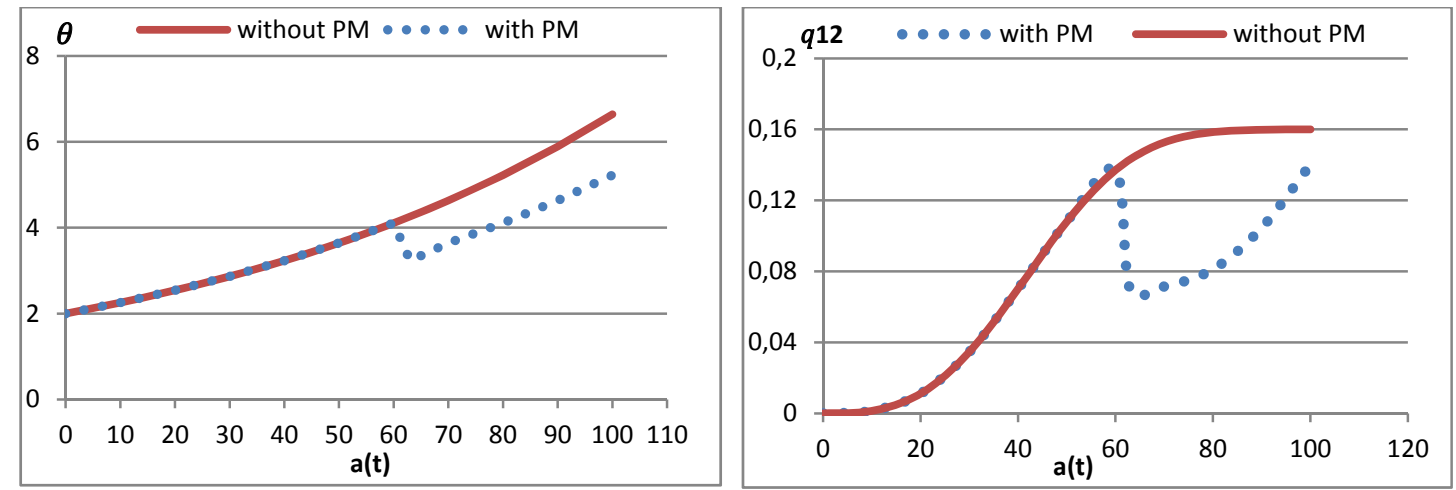

Figure 6: Effect of PM on emission index and failure rate.

From Figure 6, it is clear that PM reduces partially the emission index because the age of the machine is reduced. The same results are observed for the failure rate.

\subsection{Preventive maintenance policy}

In this section, we propose the PM policy based on the overhaul policy given in the equation (15)). The PM policy is defined by the following equation:

$$
\omega_{p}(.)=\left\{\begin{array}{cc}
1 & \text { if } \\
0 & \text { else }
\end{array} \quad a(t)>C a_{p m} \quad \text { and } \quad x(t) \geq Z 2\right.
$$

Where $C a_{p m}$ denotes the critical age level at which a PM is required. Similar to overhaul, the policy consists in doing the PM when the age of the machine reaches a critical value $C a_{p m}$. The threshold Z2, defined in the production policy, is also considered as the comfortable inventory level before PM activity.

\subsection{Results analysis}

We proceed in this section by the same resolution approach used in section 6 in order to optimize the HPP 3 parameters. It should be noted that, at this state, the optimization problem is more difficult because of the high number of factors $\left(Z 1, Z 2, C a_{o v e r}, C a_{p m}, Y\right)$. Despite this difficulty, we succeeded in finding a good model with a correlation coefficients $\mathrm{R}_{\text {adjusted }}^{2}=95.62 \%$. The results of the control parameters optimization are summarized in Table 4 for $\mathrm{q}_{41}=0.083, \sigma=0.3$ and a PM cost, noted $\mathrm{C}_{\mathrm{pm}}=25000$.

The second order model for the control policy is given by:

$$
\begin{aligned}
& \widehat{\operatorname{Cost}}_{H P P 3}=546,693-0,00927035 \times Y-3,4795 \times Z 1-129,57 \times r-1,68477 \times C a_{\text {over }}- \\
& 186,262 \times C a_{p m}+3,2774110^{-7} \times Y^{2}+0,0000311447 \times Y \times Z 1+0,00732884 \times Y \times r- \\
& 0,0000820377 \times Y \times C a_{\text {over }}+0,0242229 \times Z 1^{2}-0,00342752 \times Z 1 \times C a_{\text {over }}-0,394327 \times Z 1 \times \\
& C a_{p m}+70,9878 \times r^{2}-0,616441 \times r \times C a_{\text {over }}+0,0205111 \times C a_{\text {over }}^{2}+0,818501 \times C a_{\text {over }} \times \\
& C a_{p m}+144,155 \times C a_{p m}{ }^{2}
\end{aligned}
$$


Table 4: optimum values of the variables.

\begin{tabular}{|c|c|c|c|}
\hline Factor & $\begin{array}{c}\text { Optimum } \\
\text { values }\end{array}$ & Cost* & Confidence interval (95\%) \\
\hline$Z 1$ & 72 & \multirow{5}{*}{212.157} & \multirow{5}{*}[210.53,213.48]{} \\
\hline$Z 2$ & 35 & & \\
\hline Ca $a_{\text {over }}$ & 72 & & \\
\hline$C a_{p m}$ & 39 & & \\
\hline $\boldsymbol{Y}$ & 14304 & & \\
\hline
\end{tabular}

From Table 4, for selected system parameters, we conclude that considering the PM in the maintenance strategy, in addition to overhaul, allows reducing the total cost compared to the case where only overhaul activities are considered in the maintenance planning.

\subsection{Sensitivity analysis}

An extensive sensitivity analysis is performed in this section in order to confirm the structure of HPP3 when PM is considered. Thanks to the practical usefulness of our resolution approach, we study the influence of system parameter on the maintenance strategy of HPP3.

Figure 7 presents the variation of $Z 1$ and $Z 2$ as a function of the machine age for the basic case.

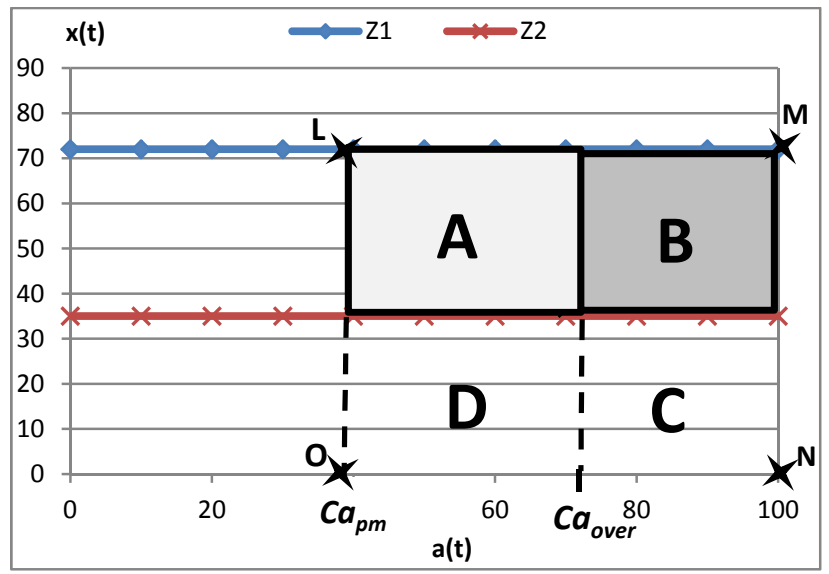

Figure 7: overhaul and PM zones.

From Figure 7, the contour (L, M, N, O) indicates the intersection between the critical ages $\left(C a_{\text {over }}, C a_{p m}\right)$ and the inventory levels $(Z 1, Z 2)$. This area is limited in the top by $Z 1$ because the inventory level cannot in any case exceed this threshold. We can devise the contour in four zones:

- Zone A: is defined by the area between the inventory thresholds $Z 1$ and $Z 2$ limited by $C a_{p m}$. In this zone, $\mathrm{PM}$ is possible because the two conditions are satisfied $\left(a(t) \geq C a_{p m}\right)$ and $(x(t) \geq Z 2)$.

- Zone B: is defined by the area between the inventory thresholds $Z 1$ and $Z 2$ limited by $\mathrm{Ca}$. In this zone, overhaul actions are possible because the two conditions are satisfied $\left(a(t) \geq C a_{\text {over }}\right)$ and $(x(t) \geq Z 2)$.

- Zone C and Zone D: in these zones, despite the fact that $\left(a(t) \geq C a_{\text {over }}\right)$ and $\left(a(t) \geq C a_{p m}\right)$, the overhaul and PM are not possible because the inventory level is less than $Z 2$. 
In the next subsection, we will show the effect of the system parameter's variation on the PM zone (zone A) and overhaul zone (zone B). The objective of this study is to provide an in-depth analysis of the influence of the system parameters on the maintenance policy when emission degradation is considered.

\subsubsection{Variation of $\mathrm{C}^{+}$and $\mathrm{C}$ -}

From Figure 8, we remark that the variation of $\mathrm{C}^{+}$and $\mathrm{C}^{-}$has an inverse effect on the size of the $\mathrm{PM}$ and overhaul zones. Results show that when $\mathrm{C}^{+}=1.4$ (respectively $\mathrm{C}^{-}=60$ ), the zone $\mathrm{A}$ and $\mathrm{B}$ covers a limited space in the study domain. When $\mathrm{C}^{+}$decreases to 0.6 (respectively $\mathrm{C}^{-}$increases to 90 ), there is a significant enlargement in the zone which means that overhaul and PM are more recommended. This enlargement is explained by the increases of the critical threshold $Z 1$ when $\mathrm{C}^{+}$decreases (respectively $\mathrm{C}^{-}$increases). Regarding $Z 2$, the increase is less significant compared to $Z 1$ and the difference $Z 1-Z 2=\Delta Z$ increases in order to reduce the emission which explain the enlargement.
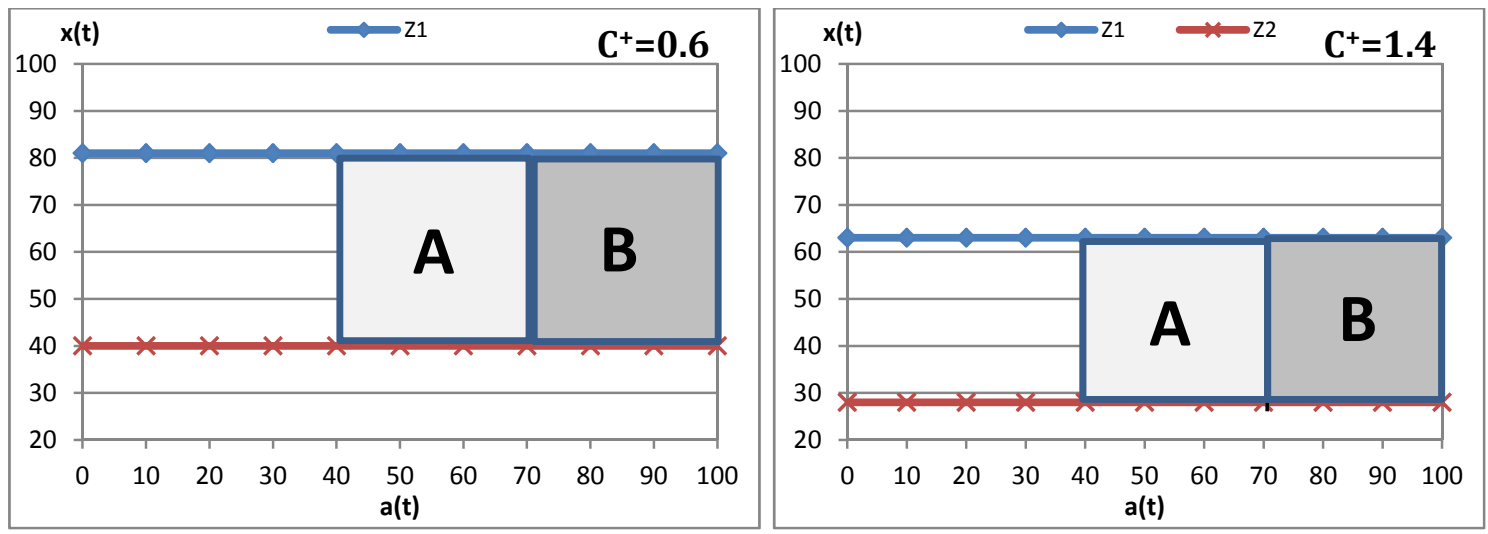

a. $\left(C^{+}\right)$
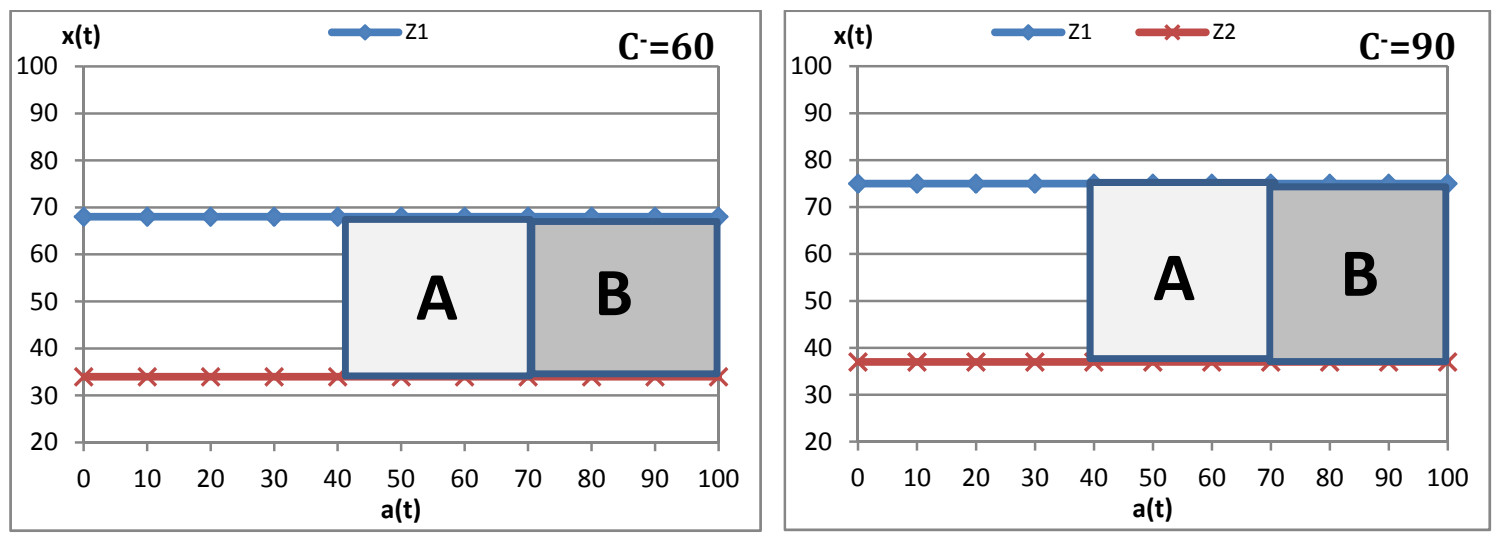

b. $\left(C^{*}\right)$

Figure 8: variation of $\mathrm{C}^{+}$and $\mathrm{C}^{-}$. 


\subsubsection{Variation of $\mathrm{C}^{\mathrm{e}}$}

As presented in Figure 9, the variation of the emission penalty has a considerable effect on the zones $\mathrm{A}$ and $\mathrm{B}$. We note that increasing the penalty from $\mathrm{C}^{\mathrm{e}}=20$ to 30 leads to an enlargement of the overhaul zone and a reduction in the PM zone. Indeed, overhaul activities are more recommended when $\mathrm{C}^{\mathrm{e}}$ increases in order to completely restore the machine to (AGAN) condition. Recall that PM has less significant effect on the emission degradation of the machine. A general remark that both maintenance activities can be done earlier when $\mathrm{C}^{\mathrm{e}}$ increases to reduces emission rate.

To finish with the emission penalty cost, we note that increasing $\mathrm{C}^{\mathrm{e}}$ increases the safety stock $\mathrm{Z} 2$ (see section 6.3) because more maintenance activities are conducted.
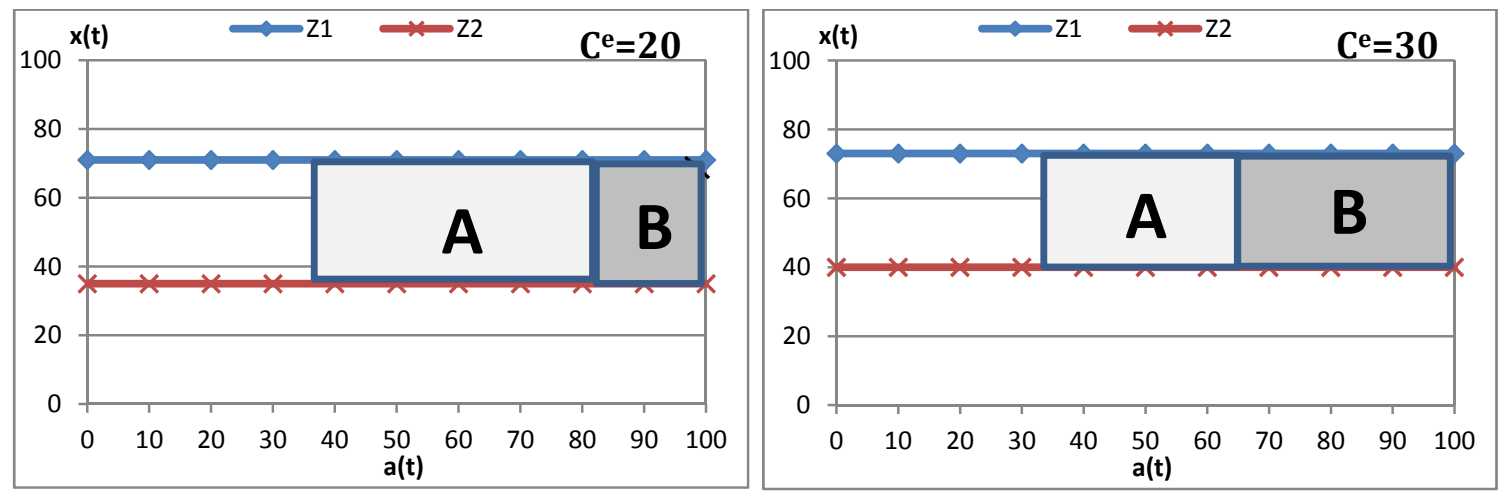

Figure 9: variation of $\mathrm{C}^{\mathrm{e}}$.

\subsubsection{Variation of $\mathrm{C}_{\mathrm{pm}}$ and $\mathrm{C}_{\text {over }}$}

In this section, we turn our attetntion to the effect of the mainenance costs on the overhaul and PM zones.

Figure 10.a presents the results of two cases of $\mathrm{C}_{\mathrm{pm}}$. From the graphics, when $\mathrm{C}_{\mathrm{pm}}$ increases from 10000 to 40000 , we remark that the space occupied by the zone A is reduced. Thus, PM is carried out only at a high level of degradation to justify its higher cost. In the other side, increasing $\mathrm{C}_{\mathrm{pm}}$ has enlarged the zone $\mathrm{B}$ in order to recommend more overhaul activities to compensate the reduction of $\mathrm{PM}$ activities.

Regarding the overhaul cost, we study the effect of two cases $\left(\mathrm{C}_{\text {over }}=125000\right.$ and $\left.\mathrm{C}_{\text {over }}=75000\right)$ on the zone A and B. From Figure 10.b, a significant reduction of the zone B is observed when $\mathrm{C}_{\text {over }}$ increases from 75000 to 125000 . Indeed, the system has a tendency to reduce overhaul interventions in order to minimize overhaul cost. Therefore, more PM is carried out which explain the enlargement in the zone A to compensate the reduction of the overhaul activities.

Another observation is that when $\mathrm{C}_{\text {over }}$ or $\mathrm{C}_{\mathrm{pm}}$ increases, the safety stock $\mathrm{Z} 2$ decreases because maintenance activities are less recommended. 

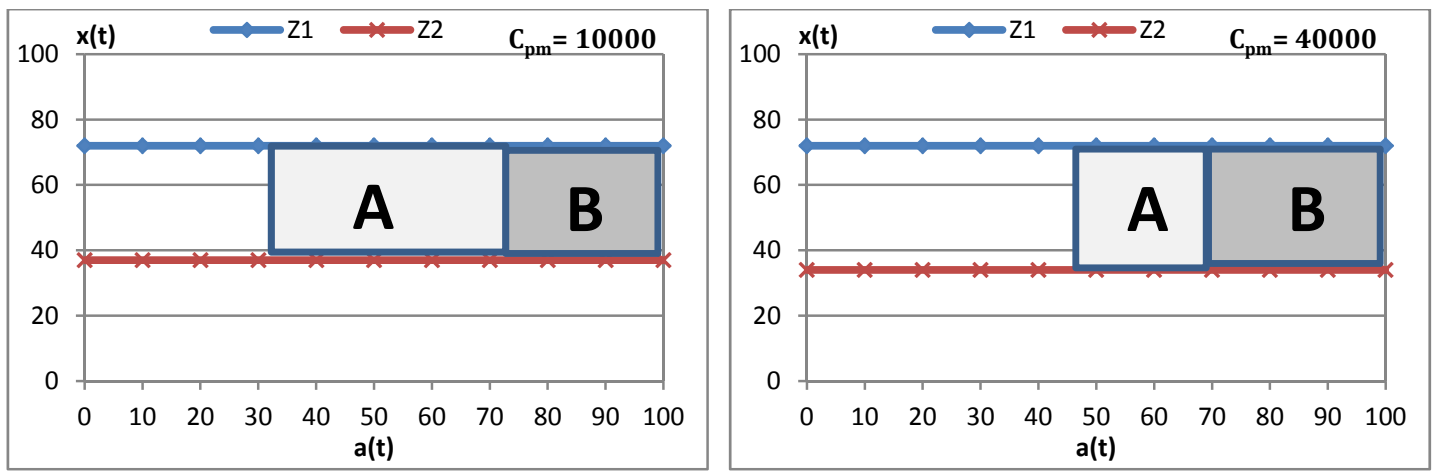

a. $\left(C_{p m}\right)$
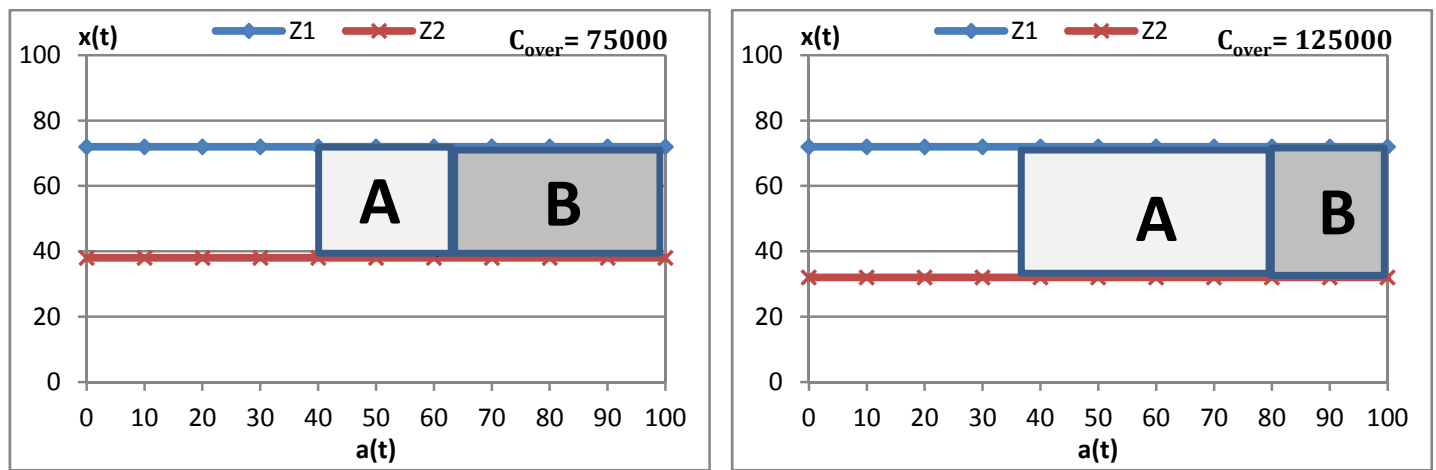

b. $\left(C_{\text {over }}\right)$

Figure 10: variation $\mathrm{C}_{\mathrm{pm}}$ and $\mathrm{C}_{\mathrm{over}}$,

\subsubsection{Variation of the adjustment parameter $\alpha$}

In this section, we focus on the effect of the variation of the adjusted parameter of the emission index trajectory $\alpha$ (see Figure 2) on the zone A and B. Figure 11 shows the results for two cases of $\alpha=0.55$ and $\alpha=0.65$.
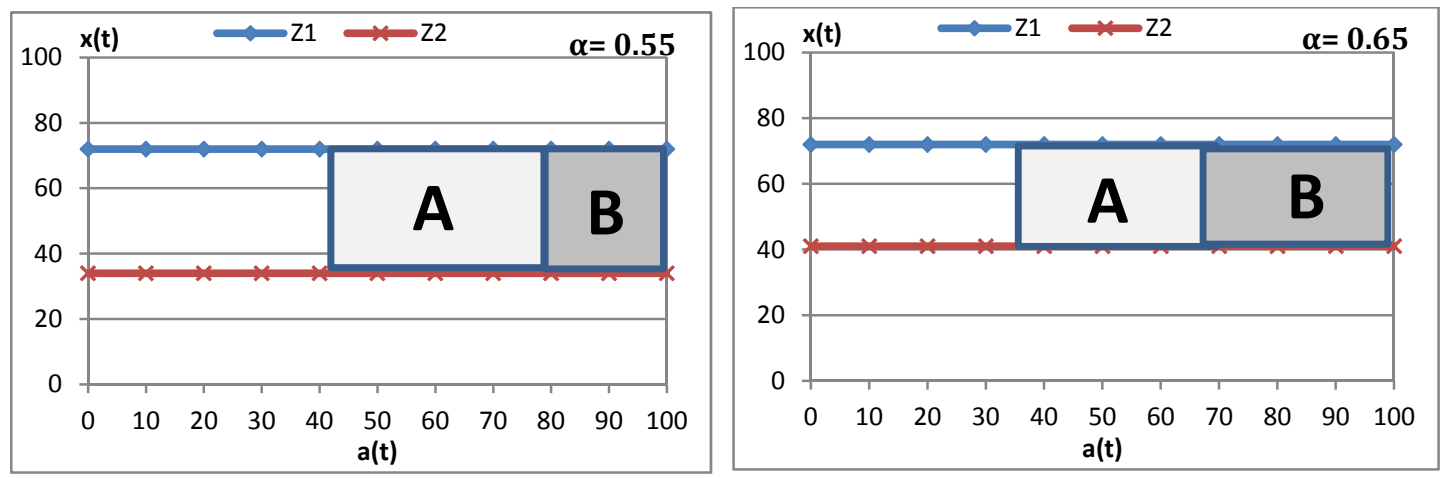

Figure 11: variation of adjustment parameter $\alpha$.

From Figure 11, the adjustment parameter $\alpha$ has an effect on the overhaul and PM zones. Indeed, when $\alpha$ increases from $\alpha=0.55$ to 0.65 , we observe a significant enlargement in the zone $\mathrm{B}$. This result is explained by the fact that increasing $\alpha$ increases the emission generated which need more 
frequent overhaul activities. In addition, recall that overhaul has a more significant effect on the machine degradation than PM which explains the reduction in zone A.

Globally, it is important to note that both maintenance activities can be done earlier when $\alpha$ increases from 0.3 to 0.4 to reduce the effect of the degradation. Therefore, the safety stock Z2 increases to protect system from backlog.

\subsubsection{Variation of the preventive maintenance efficiency}

The integration of the PM policy in HPP3 aims to study more general case of maintenance. The performance of this imperfect maintenance is modelized by the PM efficiency parameter $\sigma$. Figure 12 illustrate the variation of PM efficiency for two cases $\sigma=0.3$ to 0.4 .
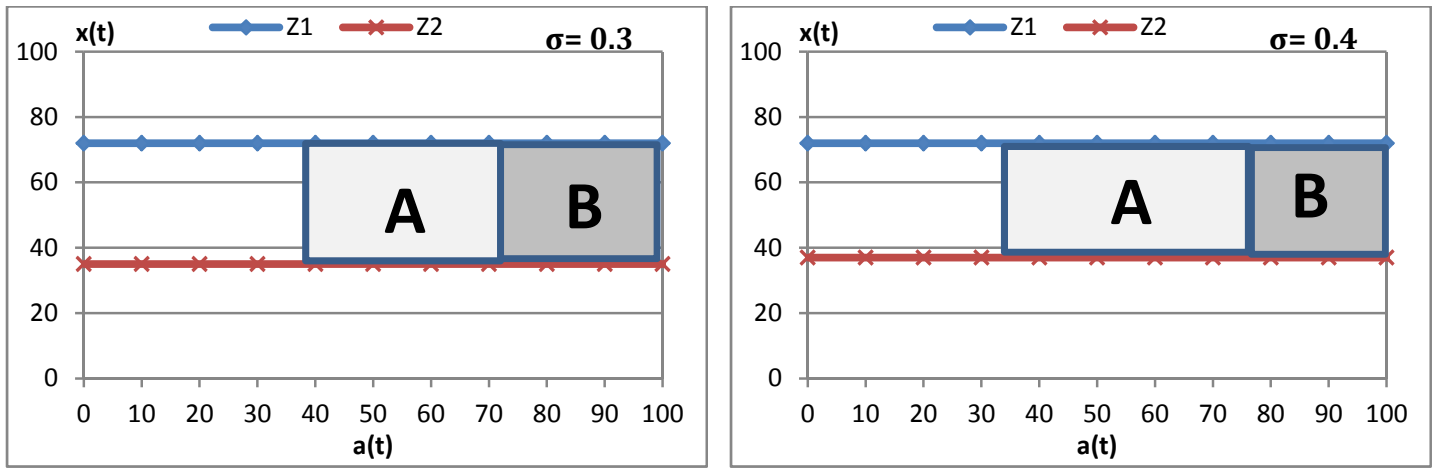

Figure 12: variation of the preventive maintenance efficiency.

For the cases studied, we observe a significant enlargement on the zone A when $\sigma$ increases from 0.3 to 0.4 . To explain, more performant PM is more recommended to benefit from it in order to reduce the effect of degradation. Hence, less overhaul activities are carried out which explain the reduction of the zone $\mathrm{B}$.

From the above analysis, we note that all results obtained make sense, and confirm our expectations. Under this section, the relationship between the system parameters and the maintenance strategy has been studied. The diversity of cases treated allowed us to form new findings on the effect of the degradation of a pollutant system. Thanks to the practical usefulness of the resolution approach, we have quantified these aspects in a realistic presentation taking into account the stochastic and dynamic behaviour of the system.

\section{Conclusion}

This work addressed the problem of production planning in interaction with the environmental issue from a perspective of degradation. The integration of environmental issue in the production policy in the presence of equipment degradation is the major contribution of this paper. We considered a degradation model that directly affects the failure rate and the emission rate which increase over time. Therefore, maintenance operations are able to restore completely (overhaul) or reduce partially (PM) the effect of the deterioration of the machine.

Three production control policies have been proposed inspired from the well-known of hedging point policy (HPP). For maintenance activities, three overhaul policies have been proposed and studied in this work. Simulation models have been developed taking into account the dynamic 
and stochastic system characteristics. Then, a numerical example has been considered in order to analyze and compare the behavior of the manufacturing system by applying each of the three proposed policies HPP1, HPP2 and HPP3.

The results showed that the HPP3 policy is better than HPP1 and HPP2. Indeed, on the one hand, HPP3 allows better inventory management facing environmental constraints. On the other hand, the maintenance strategy for this policy minimizes the risk of shortage.

The multi-hedging point policy HPP3, which takes into account the emission level, has given interesting results. With an improvement in the inventory management and maintenance strategy, HPP3 policy has led an economic gain and allows reaching the environment objectives in terms of emission balance. In addition, sensitivity analysis provides further evidence of the usefulness of this policy through the study of the effect of system parameters on the maintenance strategy.

\section{$\underline{\text { References: }}$}

- Akella, R. and Kumar, P.R., 1986. Optimal control of production rate in a failure-prone manufacturing system. IEEE Transactions on Automatic Control, AC-31 (2), 116-126.

- Bai, S.X., \& Elhafsi, M., 1997. Scheduling of an unreliable manufacturing system with nonresumable set-ups. Computers Ind. Eng., 32, 909-925.

- Barlow, R. E. \& Hunter, L., 1960, Optimal preventive maintenance policies. Operations Research, 8, 90-100.

- Battini, D., Persona, A., \& Sgarbossa, F., 2013. A sustainable EOQ model: Theoretical formulation and applications. International Journal of Production Economics, 149, 145-153.

- Berthaut, F., Gharbi, A., Kenné, J. P., and Boulet, J. F., 2010. Improved joint preventive maintenance and hedging point policy. International Journal of Production Economics, 127(1), $60-72$.

- Berthaut, F., Gharbi, A., \& Dhouib, K., 2011. Joint modified block replacement and production/inventory control policy for a failure-prone manufacturing cell. Omega, 39(6), 642654.

- Bloemhof-Ruwaard, J.M.1; van Beek, P.; Hordjik, L., Van Wassenhove, L.N, 1995. Interactions between operational research and environmental management. European Journal of Operational Research, 85, 229-243.

- Bouchery, Y., Ghaffari, A., Jemai, Z., \& Dallery, Y., 2012. Including sustainability criteria into inventory models. European Journal of Operational Research, 222(2), 229-240.

- Caramanis, M. and Sharifnia, A., 1991. Near optimal manufacturing flow controller design. International Journal of Flexible Manufacturing Systems, 3, 321-336.

- Chelbi, A., Ait-kadi, D., 2004. Analysis of a production/ inventory system with randomly failing production unit submitted to regular preventive maintenance. European Journal of Operational Research, 156, 712-718.

- Chen, X., Benjaafar, S. and Elomri, A, 2013. The carbon-constrained EOQ. Operations Research Letters, 41, 172-179.

- Chouikhi, H., Dellagi, S., \& Rezg, N. (2012). Development and optimisation of a maintenance policy under environmental constraints. International Journal of Production Research, 50(13), 3612-3620.

- Dehayem, N.F.I., Kenne, J.P. and Gharbi, A., 2009. Hierarchical Decision Making in Production and Repair/Replacement Planning With Imperfect Repairs Under Uncertainties European Journal of Operational Research,_198, 173-189.

- Dehayem, N.F.I, Kenné J.P., Gharbi A., 2011. Production planning and repair/replacement switching policy for deteriorating manufacturing systems. Int. J. Adv. Manuf. Technol., 57, 827840. 
- Dhouib, K., Gharbi, A. and Ayed, S., 2008. Availability and Throughput of Unreliable, Unbuffered Production Lines with Non-Homogeneous Deterministic Processing Time. International Journal of Production Research, 46 (20), 5651-5677.

- Dhouib, K., Gharbi, A. and M.N. Ben Aziza., 2012. Joint Optimal Production Control/Preventive Maintenance Policy for Imperfect Process Manufacturing Cell. International Journal of Production Economics, 137 (1), 126-136.

- Dobos, I., 1998. Production- inventory control under environmental constraints, International Journal of Production Economics, 56, 123- 131.

- Dobos, I., 1999. Production strategies under environmental constraints in an Arrow-Karlin model. International Journal of Production Economics, 59, 337-340.

- Dobos, I., 2001. Production strategies under environmental constraints: Continuous-time model with concave costs. International Journal of Production Economics, 71, 323- 330.

-Fernandes, F.C.F., Azeka, F.1., Barreto, M.C.M., Filho, M.G., 2009. Identifying production planning and control top authors: analysis of a survey. International Journal of Business Innovation and Research, 3 (5), 461 - 478.

- Gharbi, A., Kenne, J.-P., and Hajji, A., 2006. Operational Level-Based Policies in Production Rate Control of Unreliable Manufacturing Systems With Setups. International Journal of Production Research, 44 (3), 545-567.

- Gharbi, A., Hajji, A., and Dhouib, K., 2011, Production rate control of an unreliable manufacturing cell with adjustable capacity. International Journal of Production

Research, 49 (21), 6539-6557.

- Hajji, A., Gharbi, A., and Kenne, J.P., 2009. Joint replenishment and manufacturing activities control in two stages unreliable supply chain. International Journal of Production Research, 47 (12), 3231-3251.

- Hajji, A., Gharbi, A., Kenne, J. P., \& Pellerin, R. , 2011. Production control and replenishment strategy with multiple suppliers. European Journal of Operational Research, 208 (1), 67-74.

- Kimemia, J.G. and Gershwin, S.B., 1983. An algorithm for the computer control production in flexible manufacturing systems. IIE Transactions, 15 (4), 353-362.

- Lam, Y., Zhu, L.X., Chan, J.S.K., Liu, Q., 2004, Analysis of data from a series of events by a geometric process model. Acta Mathematicae Applicatae, 20, 263-282.

- Lavoie, P., Gharbi, A. and Kenne, J.-P., 2010. A comparative study of pull control mechanisms for unreliable homogenous transfer lines. International Journal of Production Economics, 124 (1), 241-251.

- Li, S., and Gu, M., 2012. The effect of emission permit trading with banking on firm's production-inventory strategies. Int. J. Production Economics, 137, 304-308.

- Li, S., 2013: Optimal control of the production-inventory system with deteriorating items and tradable emission permits. International Journal of Systems Science, DOI:10.1080/00207721.2013.770103

- Li, S., 2014. Optimal control of production-maintenance system with deteriorating items emission tax and pollution R\&D investment. International Journal of Production Research, 52 (60), 1787-1807.

- Love, C.E., Zhang, Z.G., Zitron, M.A., Guo, R., 2000. Discrete semi- Markov decision model to determine the optimal repair/replacement policy under general repairs. European Journal of Operational Research, 125 (2), 398-409.

- Mckay, K. N., 2003. Historical survey of manufacturing control practices from a production research perspective. International Journal of Production Research, 41(3), 411-426. - Montgomery, D.C., 2005. Design and analysis of experiments. New York: John Wiley \& Sons - Przepiórski J., 2006. Activated Carbon Surfaces in Environmental Remediation. Interface Science and Technology, 7, 421-474. 
- Parlar, M., Perry, D., 1995. Analysis of a (Q, r, T) inventory policy with deterministic and random yields when future supply is uncertain. European Journal of Operational Research, 84, 431-443.

- Radhoui, M., Rezg, N., and Chelbi, A., 2009. Integrated Model of Preventive Maintenance, Quality Control and Buffer Sizing for Unreliable and Imperfect Production Systems. International Journal of Production Research, 47 (2), 389-402.

- Rivera-Gómez, H., Gharbi, A., \& Kenné, J. P. , 2013a. Joint production and major maintenance planning policy of a manufacturing system with deteriorating quality. International Journal of Production Economics, 146 (2), 575-587.

- Rivera-Gomez, H., Gharbi, A., \& Kenné, J. P., 2013b. Joint control of production, overhaul, and preventive maintenance for a production system subject to quality and reliability deteriorations. The International Journal of Advanced Manufacturing Technology, 69 (9-12), 2111-2130.

- Sethi, S. P., and Zhang, Q., 1999. Average-Cost Optimal Policies for an Unreliable Flexible Multiproduct Machine. The International Journal of Flexible Manufacturing Systems, 11, 147157.

- Yan, H. and Zhang, Q., 1997. A numerical method in optimal production and set-up scheduling of stochastic manufacturing systems. IEEE Trans. Automat. Contr., 42, 1452-1455.

- Zhang, J. J., Nie, T. F., \& Du, S. F., 2011. Optimal emission-dependent production policy with stochastic demand. International Journal of Society Systems Science, 3 (1), 21-39. 